\title{
A TERMINOLOGIA E A TRADUÇÃo NA CONSTRUÇÃO DE VOCABULÁRIO CONTROLADO MULTILÍNGUE
}

\author{
TERMINOLOGY AND TRANSLATION IN THE CONSTRUCTION OF \\ MULTILINGUAL CONTROLLED VOCABULARY
}

Ricardo Biscalchin ${ }^{1}$

\begin{abstract}
RESUMO: Realizou-se um estudo sobre o papel da Terminologia e da Tradução na construção de vocabulário controlado multilíngue em unidades de informação, demonstrando de maneira sucinta a intersecção existente entre ambas e a Ciência da Informação. Apresenta e discute por meio de aportes teóricos metodológicos os princípios advindos da garantia cultural na recolha e na tradução terminológica, apontando a importância da aplicação conjunta dos conceitos e princípios da Ciência da Informação, da Terminologia e da Tradução, com o objetivo de auxiliar na construção de vocabulário controlado multilíngue representativo da realidade cultural e conceitual presente em cada língua. Como resultado tem-se que a correta tradução terminológica, realizada com os princípios da Terminologia, da garantia cultural e da Ciência da Informação proporciona uma representação terminológica mais compatível com a realidade de cada cultura, possibilitando a constituição de vocabulários controlados multilíngue consistentes e representativos de diversas áreas de especialidade. Concluí-se que para a construção de vocabulário controlado multilíngue deve-se utilizar de forma conjunta a estrutura assimétrica, os princípios da garantia cultural na recolha terminológica e a aplicação dos conceitos da Ciência da Informação, da Terminologia e da Tradução.
\end{abstract}

PALAVRAS-ChAVE: Vocabulário controlado multilíngue. Terminologia. Tradução. Ciência da Informação. Garantia cultural. Disseminação da informação.

\begin{abstract}
We conducted a study on the role of Terminology and Translation in building multilingual controlled vocabulary in information units, demonstrating succinctly existing intersection between both and Information Science. Presented and discussed by means of theoretical and methodological contributions arising from the principles of cultural warranty and terminology translation, emphasizing the importance of joint application of the concepts and principles of information science, Terminology and Translation, with the purpose of assisting in building multilingual controlled vocabulary representative of the cultural and conceptual reality present in each language. As a result we have that the correct terminology translation, performed with the principles of terminology, cultural warranty and Information Science provide a more compatible reality of each culture terminological representation allowing the constitution of consistent and representative multilingual controlled vocabularies in various specialty areas. It is concluded that for building multilingual controlled vocabulary should be used together with asymmetric structure, the principles of cultural warranty and the concepts of Information Science, Terminology and Translation.
\end{abstract}

KEYWORDS: Multilingual controlled vocabulary. Terminology. Translation. Information Science. Cultural Warranty. Dissemination of information.

\footnotetext{
${ }^{1}$ Bibliotecário. Mestre em Ciência, Tecnologia e Sociedade pela Universidade Federal de São Carlos UFSCar. Profissional de Apoio Técnico na Universidade Estadual de Campinas - Unicamp. CampinasSP-Brasil. E-mail: ricardo_biscalchin@yahoo.com.br

Recebido em: 21/06/2013 - Aceito em: 01/01/2014
} 


\section{INTRODUÇÃ̃}

A Ciência da Informação (CI) estuda o fluxo informacional com o intuito de compreendê-lo para melhorá-lo, por meio de teorias e ferramentas que possibilitem a organização e disseminação da informação.

Para Saracevic (1996, p. 41) a Ciência da Informação atua “[...] como um campo englobando, tanto a pesquisa científica quanto a prática profissional, pelos problemas que propõe e pelos métodos que escolheu, ao longo do tempo, para solucioná-los."

Uma das ferramentas utilizadas pela CI para organização e disseminação da informação é o vocabulário controlado. O vocabulário controlado (VC) de acordo com Lancaster (2004, p. 14) é "essencialmente uma lista de termos autorizados" cuja estrutura destina-se especialmente a: (1) controlar sinônimos optando-se por uma única forma padronizada, com remissivas de todas as outras formas; (2) diferenciar homógrafos; (3) reunir ou ligar termos cujos significados apresentem uma relação mais estreita entre si.

O VC é uma lista de termos estruturada de maneira hierárquica ou alfabética, onde os termos são controlados para evitar a presença da sinonímia, da homonímia e da polissemia, ou seja, o VC é uma linguagem artificial. Os termos presentes no VC devem ser conceitualmente representativos, de modo que possibilitem a representação da informação para posterior recuperação de maneira sucinta.

Com vistas ao objetivo da CI em disseminar a informação da maneira mais ampla possível, temos como possibilidade a construção de um vocabulário controlado multilíngue (VCM), onde os termos são apresentados em mais de uma língua em conformidade com a estrutura específica de cada língua.

Segundo Hudon (1997) e Biscalchin (2013) o VCM deve possuir inventários conceituais e terminológicos estruturalmente desenvolvidos para cada uma das línguas, representado-as de maneira equivalente a realidade cultural específica que se encontram inseridas.

Um vocabulário controlado só é verdadeiramente multilíngue, quando todo o seu conjunto de línguas encontra-se representado em conformidade com a realidade cultural específica presente em cada língua. 
Para a representação da informação em diferentes línguas, recorre-se além do conjunto de normas e diretrizes para construção de VC e VCM, para a Terminologia e a Tradução.

A Terminologia é a "ciência que estuda a estrutura, a formação, o desenvolvimento, o uso e a gestão das terminologias nos diferentes domínios" (ISO 1087, 2000, p. 2).

A Terminologia ${ }^{2}$ relaciona o estudo dos termos para a representação dos conceitos, possibilitando a representação das linguagens de especialidade, por meio de distintas abordagens, como a Teoria Geral da Terminologia (TGT), a Teoria Comunicativa da Terminologia (TCT), a Socioterminologia e a Teoria Sociocognitiva da Terminologia (TST).

Nakayama (1996) e Cervantes (2004) afirmam que a Terminologia e a Ciência da Informação têm em comum as abordagens sobre a linguagem de especialidade e os termos na elaboração de produtos terminográficos aplicáveis em vocabulários controlados.

Deste modo, a Terminologia: “enquanto ferramenta linguística básica de comunicação entre especialistas [...] [é] vital para troca de conhecimento e transferência de tecnologia [...]" (CERVANTES, 2004, p. 59) e, a CI se ocupa da disseminação seletiva da informação a usuários especializados ou não, com o uso de instrumentos de representação temática na indexação e recuperação por assuntos.

A Terminologia e a CI possuem em comum a busca pela comunicação e a disseminação da informação, colaborando com o processo de desenvolvimento científico-tecnológico.

Para a construção do VCM recorre-se também a Tradução, que se apresenta como essencial para a representação dos termos e seus conceitos de maneira coerente em cada língua.

A tríade Ciência da Informação, Terminologia e Tradução possibilita a construção de VCM que seja representativo de cada língua e cultura, de modo a auxiliar na disseminação da informação para distintas culturas e sociedades.

\footnotetext{
${ }^{2}$ Utilizaremos o termo Terminologia com ' $\mathrm{T}$ ' (maiúsculo) quando nos referirmos a ela como ciência e com 't' (minúsculo) quando nos reportamos a ela como metodologia.
} 


\section{A TERMINOLOGIA E A TRADUÇÃO NA CONSTRUÇÃO DE VOCABULÁRIO CONTROLADO MULTILÍNGUE}

O conjunto lexical existente em cada repertório terminológico e língua, em um vocabulário controlado multilíngue, devem ser analisados, sendo os termos, a representação semântica da informação.

A terminologia, de acordo com Cervantes (2004), possui pontos de interface com o vocabulário controlado como instrumento da Ciência da Informação. Estes pontos surgem por meio de objetos, atividades, finalidades e instrumentos comuns ou similares entre a Terminologia e a Ciência da Informação.

Krieger (2005, p. 1) afirma que Terminologia é

[...] uma área de conhecimentos e de práticas, cujo principal objeto de estudos teóricos e aplicados são os termos técnico-científicos. Em sua face teórica, a Terminologia ocupa-se da descrição da gênese e dos modos de constituição e funcionamento das unidades lexicais especializadas. Estas são assim denominadas porque se constituem e são utilizadas no âmbito de atividades profissionais especializadas, cumprindo a missão de veicularem conceitos próprios de cada área do conhecimento.

A International Standardization Organization (ISO) em sua norma técnica ISO 1087 (2000, p. 2) afirma que a Terminologia pode ser definida, enquanto disciplina científica, como "ciência que estuda a estrutura, a formação, o desenvolvimento, o uso e a gestão das terminologias nos diferentes domínios”.

O foco da terminologia é a realização da descrição de áreas de especialidade por meio de termos conceitualmente representativos, através de um caráter multidisciplinar estabelecido pelo diálogo entre áreas técnicas e científicas, como a Ciência da Informação e a Tradução.

De acordo com a norma ISO 1087 (2000, p. 6) "termo" é a "designação verbal de um conceito geral em um domínio específico".

O objeto da terminologia é o termo técnico-científico de linguagem de especialidade, com foco nos aspectos pragmático, cognitivo e linguístico.

Cabré (2005) expõe em síntese que a Terminologia é:

- uma disciplina que se ocupa dos termos especializados;

- o conjunto de diretrizes ou princípios que regem a recompilação de termos; 
- produto gerado pela prática, caracterizado pelo conjunto de termos de uma área especializada para fins de expressão e comunicação profissional.

A terminologia busca por meio do uso de linguagens artificiais controladas possibilitar a comunicação mais efetiva e eficiente para a formação de uma linguagem de especialidade.

Cervantes (2004, p. 56) observa que

[...] há pontos de contiguidade entre os propósitos das duas ciências: tanto a Terminologia como a Ciência da Informação têm como finalidade atender os usuários em suas necessidades de informação. Desse modo, as duas ciências possuem diversos instrumentos comuns ou similares para a realização de suas atividades, tais como os dicionários, glossários, enciclopédias, sistemas de classificação, tesauros, normas, fontes literárias, as informações dos profissionais e especialistas da área, entre outros.

A intersecção entre a CI e a Terminologia é primordial para a construção de vocabulários controlados multilíngue para fins de disseminação da informação aos usuários de distintas línguas.

Dentre as distintas correntes teóricas da Terminologia, destacamos a Teoria Comunicativa da Terminologia (TCT). A TCT, apresentada por Maria Teresa Cabré (1993), ressalta a importância dos aspectos comunicativos da linguagem para fins de disseminação da informação.

A TCT foi destacada pelo fato de reconhecer que o conteúdo dos termos não é fixo ou imutável, mas distinto para cada contexto e cultura que representam, pretendendo

[...] dar conta dos termos como unidades ao mesmo tempo singulares e similares a outras unidades de comunicação, dentro de um esquema global de representação da realidade, admitindo a variação conceitual e denominativa, e tendo em conta a dimensão textual e discursiva dos termos. (CABRÉ, 1999, p. 136).

Para que o VCM represente a informação de modo igualitário nas diferentes línguas e culturas, além dos conceitos da Ciência da Informação e da Terminologia, é de extrema importância a Tradução.

A Tradução teve sua origem na Alemanha na metade dos anos 80 através dos nomes de Hans P. Krings, Frank G. Königs, Hans H. Hönig e Paul Kußmaul. 
Os princípios da tradução consistem em representar a informação traduzida com a mesma cognição da língua fonte. De acordo com Schleiermacher (2007, p. 246)

[...] o tradutor tem que colocar como meta proporcionar ao seu leitor uma imagem e um prazer semelhantes aos que a leitura da obra na língua original busca o homem culto, [...] que conhece suficientemente a língua estrangeira sem que deixe de lhe parecer estranha e já não necessita, como os alunos, repensar na língua materna cada parte antes de compreender o todo, mas, inclusive quando mais sem travas desfruta das belezas de uma obra, siga notando sempre a diferença entre a língua em que está escrita e a sua língua materna.

Por meio da tradução, os termos do VCM devem representar a informação conforme a especificidade e características de cada língua, apresentando ao usuário termos representativos com a mesma sensação e cognição que estes teriam na representação e estruturação da língua fonte.

Schleiermacher (2007, p. 261) afirma que

[...] se o tradutor quer fazer falar um autor de obras cênicas como se este houvesse escrito originalmente na língua da tradução, terá muitas coisas que nem sequer poderá fazer expressar, pois, não são nativas deste povo e, por isso, tampouco tem na língua algum signo.

Relativo à construção de VCM, a tradução terminológica também exige cuidados e conhecimento dos envolvidos no desenvolvimento dos sistemas de organização da informação (bibliotecários, entre outros sujeitos) acerca da área de conhecimento, da cultura e da língua em que os termos serão tratados.

A questão cultural presente em cada língua deve ser garantida, respeitada e validada. Sobre a questão cultural, devemos nos atentar aos princípios da garantia cultural, que conforme retrata Beghtol (2002, p. 511), qualquer tipo de representação da informação e/ou sistema de organização pode ser maximamente apropriado e útil para indivíduos em algumas culturas, apenas se for baseado em pressupostos, valores e predisposições daquela cultura.

A tradução terminológica em um VCM não se resume, portanto apenas ao processo de tradução em si, mas também a consideração das diferenças culturais existentes entre as línguas, devendo o tradutor realizar as adaptações necessárias para contemplar as características de cada cultura, de modo a representar a informação para os distintos usuários de modo igualitário e condizente com cada realidade cultural. 
"Uma boa tradução não deve apenas expressar o mesmo conteúdo que o texto de partida, mas fazê-lo com as formas que um falante nativo da língua de chegada utilizaria" (BARROS, 2006, p. 23).

No processo de tradução de um VCM, a língua-fonte (base para a realização da tradução) disponibiliza a estrutura terminológica para a tradução na(s) língua(s)-alvo. Os termos presentes na língua-fonte devem ser traduzidos e adaptados para a(s) língua(s)-alvo, seguindo e respeitando o contexto sócio, histórico, cultural de cada língua.

Nesta etapa, a terminologia aparece para sistematizar as unidades conceituais e suas relações lógico-semânticas, de modo que sejam representativas do conteúdo documentário, a partir de termos técnico-científicos semanticamente condizentes com a área de especialidade, formando, assim, um conjunto de termos válidos.

Cabré (1999, p. 215) esclarece que no momento de se estabelecer as equivalências terminológicas entre as distintas línguas, quatro ocorrências podem suscitar:

1. que a língua-alvo não disponha de uma terminologia própria para a área de especialidade pelo fato de os especialistas não utilizarem sua língua para tratar da temática;

2. que existam conceitos sem denominações cunhadas em uma língua. A ausência de terminologia ou a presença (por empréstimo) se reduzam a casos pontuais;

3. que para um conceito existam várias denominações e que estas tenham o mesmo ou distinto valor pragmático ou de frequência, com a conseguinte necessidade de selecionar a mais adequada a cada circunstância ou de reduzir as distintas possibilidades a poucas;

4. que a conceitualização de uma matéria seja distinta em comunidades de línguas diferentes, sendo inviável se pensar em uma tradução literal supondo que toda unidade da língua A tenha uma unidade equivalente na língua $B$.

Na primeira ocorrência, a autora apresenta a possibilidade de a língua-alvo não possuir uma terminologia própria para uma área de especialidade, seja em virtude desta área não estar desenvolvida, ou pelo fato de utilizarem termos advindos de outra(s) língua(s).

A segunda ocorrência apresenta a possibilidade de uma área de especialidade recorrer a alguns termos advindos de outras línguas para representar alguns conceitos, o que reforça novamente à necessidade de conhecimento da cultura da área de especialidade a ser representada. 
A terceira ocorrência traz a preocupação referente à existência de várias denominações para a representação de um conceito, levando a necessidade de seleção do termo mais adequado para a representação da informação no VCM, devendo os outros termos expressivos ser inseridos como remissivas.

Estas três ocorrências ressaltam a importância de avaliar a questão cultural da área de especialidade para a realização da recolha terminológica para cada língua, de modo que sejam utilizados apenas termos compatíveis com a realidade dos usuários e da área de especialidade.

Acerca da quarta ocorrência verifica-se a refutação no emprego da concepção de vocabulários controlados multilíngue a partir da estrutura idêntica e simétrica de termos, pois uma tradução literal de uma língua para a outra, levaria a necessidade de "inventar" termos ou suprimi-los, para que contemplem a estrutura da língua fonte.

Para a contemplação dos princípios advindos da garantia cultural, da Terminologia e da Tradução é necessário a adoção da estrutura assimétrica, pois é por meio desta estrutura que os termos poderão ser dispostos para a representação da informação conforme a especificidade de cada língua e cultura.

É essencial ao tradutor conhecer o conjunto terminológico da área de especialidade que irá traduzir tanto na língua-fonte como na(s) língua(s)-alvo. No âmbito documentário, tais competências e habilidades são normalmente atribuídas e requeridas ao bibliotecário, um dos sujeitos envolvidos na tarefa de elaboração de vocabulários controlados multilíngue. Além da presença do bibliotecário, Cabré (1999) aponta a necessidade da participação de terminólogos, especialistas das áreas de conhecimento e especialistas em linguagem.

O ideal no momento de construção de um vocabulário controlado multilíngue é contar com a presença de especialistas nas áreas de Biblioteconomia, Linguística, Terminologia, Ciência da Computação, Tradução e da área de especialidade a ser representada.

A tradução terminológica deve ser realizada de maneira cuidadosa para que equívocos sejam evitados, como o exemplo da figura abaixo: 
Tradução da língua portuguesa (língua-fonte) para a língua inglesa (língua-alvo)

\section{Jogar uma partida contra Camarões}

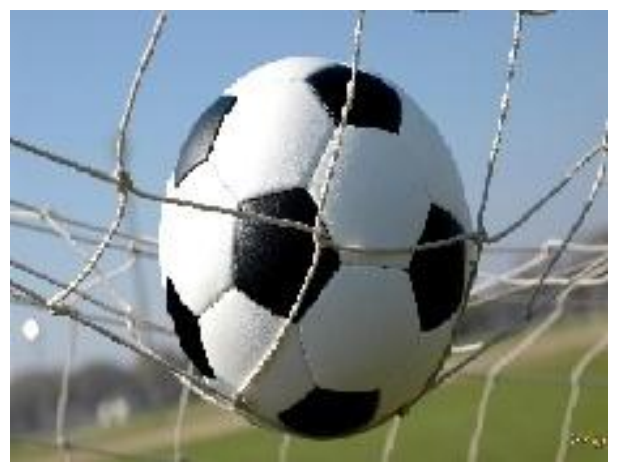

Tradução Equivocada: Play a departure against Shrimps Tradução Correta: Play a game against Cameroon

Fonte: Portal do tradutor profissional ${ }^{3}$.

No exemplo acima, a tradução de uma simples frase é realizada de uma maneira equivocada, devido à falta de avaliação da questão cultural e conceitual dos termos adotados. Em um vocabulário controlado o uso de termos não representativos de uma área de especialidade, levaria ao estranhamento por parte do usuário da língua-alvo (neste caso a língua inglesa) sobre a terminologia adotada, e a prováveis equivalências e associações incorretas e incompatíveis com a realidade da área de especialidade nesta língua, levando a interpretações equivocadas e perda de qualidade na representação e recuperação da informação.

Outra dificuldade que pode surgir é a ausência de termos técnico-científicos de uma língua para a outra, por diferenças estruturais e culturais da área de especialidade. Boccato (2005) revela que isso acontece na área de Fonoaudiologia, pois:

- na língua portuguesa temos o termo Fonoaudiologia (português do Brasil e de Portugal);

\footnotetext{
${ }^{3}$ Disponível em: <http://www.terminologia.com.br/2008/03/13/perolas-da-traducao/\#comments>. Acesso em: 09 jun. 2013.
} 
- na língua espanhola temos, respectivamente, os termos Logopedia (espanhol europeu) e Fonoaudilogía (espanhol latino);

- na língua inglesa não há correspondência linguística para o referido termo, pois a concepção de tal área do conhecimento é de outra natureza.

Pode-se notar a variação de termos entre as línguas. Na língua portuguesa temos a presença de um único termo, fonoaudiologia, enquanto que na espanhola, dois termos designativos para duas culturas, a européia e a latina, respectivamente os termos Logopedia e Fonoaudilogía. Neste caso deve-se avaliar o contexto sócio, histórico e cultural dos usuários, adotando um termo favorito, e fazendo uma remissiva para o outro.

Já na língua inglesa, esta área do conhecimento é de outra natureza, devendo no momento da construção do VCM ser estruturada tal qual seria em um vocabulário controlado monolíngue em inglês. Este caso nos permite reafirmar a importância da adoção da estrutura assimétrica e a aplicação dos princípios da garantia cultural para a representação terminológica da informação.

Outra situação que pode ocorrer é referente às áreas de alta tecnologia e que nem sempre se encontram em todos os países, levando ao empréstimo de termos de outra língua. Ribeiro (2004, p. 165) afirma que

[...] é cada vez mais frequente que muitos termos sejam mantidos em inglês, muitas vezes a pedido dos próprios clientes, que recebem treinamento no exterior e acostumam-se a utilizar a terminologia no idioma original. Caso não receba essa instrução, cabe ao tradutor cunhar o termo e validá-lo com o cliente ou especialistas.

Novamente se apresenta a questão cultural, pois a tradução terminológica não deverá ser realizada quando os usuários da(s) língua(s)-alvo já tiverem incorporado o termo utilizado em outra língua à sua cultura. A tradução neste caso seria mais um complicador do que um facilitador na representação e disseminação da informação.

\section{CONSIDERAÇõES FINAIS}

A correta tradução terminológica, realizada com os princípios da Terminologia, da garantia cultural e da Ciência da Informação resulta em uma representação 
terminológica mais compatível com a realidade de cada cultura, possibilitando a constituição de vocabulários controlados multilíngue consistentes e representativos de diversas áreas de especialidade, objetivando alcançar precisão semântico-conceitual em sistemas de recuperação da informação.

Esta preocupação com a Terminologia e a Tradução na construção de VCM se justifica pela crescente produção científica, a globalização e a facilidade de acesso as unidades de informação por usuários presentes nos mais distintos países e culturas, o que faz com que o vocabulário controlado multilíngue tenha cada vez mais

[...] importância significativa por ampliar as possibilidades de recuperação dos conteúdos dos documentos indexados nos mais variados sistemas de recuperação da informação em todo mundo, a partir do uso de [um vocabulário controlado] construído em mais de uma língua, resultando numa visibilidade maior da produção científica e, consequentemente, na geração de novos conhecimentos em CTS (BISCALCHIN; BOCCATO, 2012, p. 289).

A tradução terminológica deve ser realizada seguindo os princípios apresentados, pois, na contemporaneidade, o léxico especializado deixou de se caracterizar pela exclusividade designativa, seja em relação ao universo das distintas áreas de conhecimento, seja mesmo em relação ao léxico geral, como atestam os múltiplos sentidos terminológicos registrados nos verbetes dos dicionários gerais de língua, como é o caso de vírus e rede, que possuem sentidos específicos da biologia, mas que se modificam quando o contexto é a informática (KRIEGER, 2006, p. 192).

Considerando a interdisciplinaridade entre a Terminologia, a Tradução e a Ciência da Informação, reforça-se a importância do conhecimento, por parte do tradutor e do bibliotecário sobre a terminologia da área a ser representada e traduzida, visto a gama de perspectivas conceituais que um termo pode conter em diversas línguas, provenientes de distintos contextos sócio, histórico, culturais.

É importante ressaltar a dificuldade em conhecer múltiplas áreas e, muitas vezes, a escassez de dicionários multilíngue, levando aos tradutores terminológicos e, particularizando o nosso universo profissional, aos bibliotecários a atuarem

[...] como verdadeiros 'pesquisadores-exploradores' das linguagens especializadas. Desse modo, produzem seus próprios materiais de apoio e 'fazem [e/ou consultam] glossários' (KRIEGER; FINATTO, 2004, p. 179). 
A terminologia considera a articulação do aspecto linguístico aos quesitos: comunicativo e pragmático, existentes também nas linguagens de especialidade. O que permite afirmar que

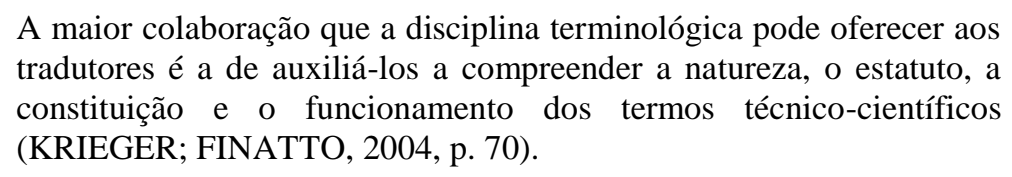

A maior colaboração que a disciplina terminológica pode oferecer aos tradutores é a de auxiliá-los a compreender a natureza, o estatuto, a constituição e o funcionamento dos termos técnico-científicos (KRIEGER; FINATTO, 2004, p. 70).

Assim, recomenda-se para a construção de vocabulário controlado multilíngue a aplicação de forma conjunta da estrutura assimétrica, dos princípios da garantia cultural para a recolha terminológica, e a aplicação dos conceitos da Ciência da Informação, da Terminologia e da Tradução.

A aplicação deste conjunto possibilitará ao bibliotecário, a representação temática para o acesso e uso da informação em sistemas automatizados de recuperação por assunto nas diferentes línguas, de maneira igualitária, possibilitando aos usuários locais e remotos, oriundos das mais variadas regiões do mundo e culturas, a recuperação da informação de modo similar em suas buscas, excluindo a língua como empecilho no desenvolvimento científico-tecnológico.

Acredita-se que deste modo as unidades de informação que adotarem estes princípios e conceitos na construção de VCM ampliarão de maneira gradual sua participação na disseminação e produção do conhecimento científico, ampliando sua visibilidade e a da instituição.

\section{REFERÊNCIAS}

BARROS, L. A. Aspectos epistemológicos e perspectivas científicas da terminologia. Ciência e Cultura, v. 58, n. 2, p.22-26, 2006. Disponível em: $<$ http://cienciaecultura.bvs.br/scielo.php?script=sci_arttext\&pid=S000967252006000200011\&lng=pt\&nrm=iso ISSN 0009-6725>. Acesso em: 06 jun. 2013.

BEGHTOL, C. A proposed ethical warrant for global knowledge representation and organization systems. Journal of Documentation, London, v. 58, n. 5, p. 507-532, 2002.

BISCALCHIN, R. Construção de vocabulário controlado multilíngue: um estudo de possibilidades no contexto da garantia cultural e pela perspectiva da Terminologia. 2013. 133 f. Dissertação (Mestrado) - Curso de Ciência, Tecnologia e Sociedade, Universidade Federal de São Carlos, São Carlos, 2013. 
BISCALCHIN, R.; BOCCATO, V. R. C. Os tesauros multilíngues pelas perspectivas da Ciência, Tecnologia e Sociedade: possibilidades de construção e uso. In: HOFFMANN, W. A. M.; MIOTELLO, V.; PEDRO, W. J. A. Tecendo a Interdisciplinaridade no campo CTS. São Carlos: Pedro \& João Editores, 2012. p. 279-300.

BOCCATO, V. R. C. Avaliação de linguagem documentária em Fonoaudiologia na perspectiva do usuário: estudo de observação da recuperação da informação com protocolo verbal. 2005. 239 f. Dissertação (Mestrado em Ciência da Informação) Faculdade de Filosofia e Ciências, Universidade Estadual Paulista, Marília, 2005. Disponível em: <http://www.cgb.unesp.br>. Acesso em: 18 maio 2013.

CABRÉ, M. T. La terminología: teoria, metodología, aplicaciones. Traducción castellana de Carles Tebé. Barcelona: Ed. Antártica/Empúres, 1993.

CABRÉ, M. T. La terminología: representación y comunicación: elementos para uma teoría de base comunicativa y otros artículos. Barcelona: IULA, 1999

CABRÉ, M. T. La terminología: representación y comunicación: elementos para una teoria de base comunicativa y otros artículos. Barcelona: Institut Universitari de Lingüística Aplicada, 2005.

CERVANTES, B. M. N. Contribuição para a terminologia do processo de inteligência competitiva: estudo teórico e metodológico. 2004. 183 f. Dissertação (Mestrado em Ciência da Informação) - Faculdade de Filosofia e Ciências, Universidade Estadual Paulista, Marília, 2004.

HUDON, M. Multilingual thesaurus construction: integrating the views of different cultures in one gateway to knowledge and concepts. Knowledge Organization, Würzburg, v. 24, n. 2, p. 84-91, 1997.

INTERNATIONAL ORGANIZATION FOR STANDARDIZATION (ISO). ISO 10872000: Terminology work - vocabulary. Genéve: ISO, 2000. Disponível em: <http://www.iso.org/iso/catalogue_detail.htm?csnumber=20057>. Acesso em: 12 jun. 2013.

KRIEGER, M. G. Terminologias em construção: procedimentos metodológicos. Termisul-Ufrgs, Unisinos. 2005. 6 p. Disponível em: <http://www6.ufrgs.br/termisul/biblioteca/artigos/artigo_ABECAN_2005_KRIEGER.p df>. Acesso em: 08 jun. 2013.

KRIEGER, M. G. Do ensino da terminologia para tradutores: diretrizes básicas. Jornal UFSC, Florianópolis, 2006. Cadernos de Tradução, p. 189-206. Disponível em: <http://journal.ufsc.br/index.php/traducao/article/view/6862/6413>. Acesso em: 12 jan. 2012.

KRIEGER, M. G.; FINATTO, M. J. B. Introdução à terminologia: teoria \& prática. São Paulo: Contexto, 2004. 223 p. 
LANCASTER, F. W. Indexação e resumos: teoria e prática. 2. ed. rev. e ampl. e atual. Brasília: Briquet de Lemos/Livros, 2004.

NAKAYAMA, H. Terminologia aplicada à ciência da informação: da produção de vocabulário técnico-científico bilíngüe (japonês-português), na área do ensino da língua japonesa. 1996. 321 f. Tese (Doutorado em Lingüística) - Faculdade de Filosofia Letras e Ciências Humanas, São Paulo, 1996.

RIBEIRO, G. C. B. Tradução técnica, terminologia e lingüística de corpus: a ferramenta Wordsmith Tools. Cadernos de Tradução, Florianópolis, v. 2, n. 14, p.159-174, 2004. Disponível em: <http://www.periodicos.ufsc.br/index.php/traducao/issue/view/437>. Acesso em: 02 jun. 2013.

SARACEVIC, T. Ciência da informação: origem, evolução e relações. Perspectivas Ciência da Informação, Belo Horizonte, v. 1, n. 1, p. 41-62, 1996.

SCHLEIERMACHER, F. D. E. Dos diferentes métodos de traduzir. Tradução de Mauri Furlan. Florianópolis: UFSC, 2007. 19 f. Disponível em: <http://www.periodicos.ufrn.br/index.php>. Acesso em: 20 jun. 2013.

\section{Como citar este documento:}

BISCALCHIN, Ricardo. A terminologia e a tradução na construção de vocabulário controlado multilíngue. Rev. digit. bibliotecon. cienc. inf., Campinas, SP, v.12, n.2, p.136-149, maio/ago. 2014. ISSN 1678-765X. Disponível em: <http://www.sbu.unicamp.br/seer/ojs/index.php/rbci>. Acesso em: 30 maio 2014. 